\title{
Governance in a Global Environment (Position Paper in Summary)
}

\author{
Alan S. MILWARD
}

A) Historians and economists seem, from the existing literature, to have a wide area of agreement on the ingredients of international economic interdependence. They could be listed as follows.

a) An increase in the ratio of foreign trade values to GNP

b) An increase in the ratio of capital inflows and outflows to GNP

c) An increase in permanent migrants

d) An increase in the temporary movement of persons across frontiers

e) An increase in other forms of cross-frontier communications (telephone messages, postal items, electronic communications, etc.)

f) Submission to technological innovations which increase the permeability of frontiers, or render them inoperative.

B) All measurement of these phenomena over time, insofar as it is possible, reveals two persistent characteristics, more dominant than any trend towards greater interdependence. Firstly, the disparity between countries which on these definitions record high levels of interdependence and those which record low levels is very wide. Secondly, the gap between the most interdependent and the least remains in the same proportion in the 1990s as it was in 1912 on most measurements, although the names of the most and least interdependent change according to the characteristic being measured. On most of these counts, for example, the Netherlands and Belgium appear both in 1912 and in the 1990s as the most interdependent of European economies, Bulgaria, Romania and Serbia as among the least, and the statistical gap between them has not closed except in the case of foreign trade as a ratio of GNP. Size of country and resources obviously is an important determinant of such measurements, but larger European countries (France, Germany) still show a similar overall ranking in relationship to the Netherlands and to Serbia, for example, as they did in 1912. The only European country which significantly narrows the gap with the most interdependent is Spain.

C) If there is a trend towards increasing economic interdependence over the twentieth century it is only apparent on some of these characteristics and it has been a very erratic one. Thus, whereas former eastern bloc countries now show much higher ratios of foreign trade values to GNP than in 1912, in 1955 those ratios were lower than in 1912. Germany, of course, shows much lower ratios in the 1930s than in 1912. On most estimates, permanent migration has not again reached its levels of 1912, although the temporary movement of persons has shown great increases since that date. The evidence from international capital flows is unreliable, since virtually all foreign capital investment before the First World War was private investment. However, the proportion of GNP recycled into foreign investment was much higher for France and 
the United Kingdom before 1910 than it has been at any time since 1945 for the USA, Britain or France. The Russian Empire was then the greatest single receiver of foreign capital. Current levels of foreign investment (direct or portfolio) into Russia fall far short of their level under the gold standard. On most counts therefore it is by no means clear that interdependence is more advanced, or even as advanced, in its impact on national governance in Europe than it was ninety years ago.

D) Attempts to measure the trend towards interdependence by more sophisticated methods have generally deteriorated into nonsense. Usually they have involved estimating the degree of convergence (or divergence) between macroeconomic entities such as prices, wages, and interest rates over long periods of time. They reveal a fluctuation between convergent and divergent trends. Because over the whole period 1912-1999 it has been an objective of most governments to manipulate these entities in the interests of electoral politics it can not be acceptable to use them as normative measurements over the whole period.

E) We are left therefore with a strong presumption that, although there may indeed have been an overall, but far from linear, trend towards interdependence in the twentieth century, it has not been so strong as to justify the present view that it is a threat to national governance of wholly new proportions.

F) Where this threat is specified as coming from the impact of technology on frontiers it is only in the military-strategic sphere that technological developments have eliminated frontier barriers. New forms of transport and electronic technology can still be controlled on frontiers, if states so choose.

G) The two great differences in interdependence in this decade compared to earlier ones are in the way foreign trade is carried out in higher per capita income countries and in the value of financial movements, not linked to foreign trade settlements or long-term investment, across frontiers. Roughly $60 \%$ of the value of the foreign trade of the most developed economies is now carried on by the international transactions of the largest two hundred transnational companies. The value of foreign exchange transactions is now estimated at more than $\$ 30,000,000,000,000$ (US) daily. Only about ten per cent of that value is backing commercial transactions. These are the two new elements in interdependence, at least in scale, although the advantages of the second could presumably be foregone by an assertion of state authority akin to that which sacrificed Germany's foreign trade sector in the 1930s.

$\mathrm{H})$ Leaving aside the question of whether larger units of governance, and monetary unions, do improve total factor productivity and GNP growth rates, there is little sound historical evidence to suggest that the changes in the governance and monetary arrangements of western Europe are a response to the diminution of the power of national governance by an overall process of globalisation. They may be desirable, but they have not been compelled by international economic developments. States have chosen to let their frontiers become increasingly permeable. Long-run measurements of interdependence suggest one reason for this. A higher degree of interdependence in western European states has correlated over time with a higher per capita income. There would seem therefore to be good reasons why the choice of 
permeability would generally be the preferred choice of a parliamentary democracy. It tends in favourable economic circumstances, which have not by any means applied throughout the period 1912-1999, to win elections. It is not the unpopular choice forced on electorates that it is so often represented as being. The corollary, of course, is that in different economic circumstances states can make other choices. Interdependence is reversible, although the semantic change to 'Globalisation' is designed to suggest that it is not. National and regional governance could retake the latitude which they have surrendered by treaty to supranational governance in Europe.

I) This being the situation, a much more exact economic calculus of the gains and losses involved in switches between high and low degrees of interdependence, which is the correct picture of twentieth century Europe, is needed. Teleological assumptions about economies of scale, size of units of governance, and causes of total factor productivity growth impede our economic and political understanding of why these switches have been made, and even more so our ability to forecast a future trend. They only help to make the switches possible. European Monetary Union will restrict the latitude of national governance only so long as nations want it to. The euro may become the first major international currency not to be backed by one national government, but it could be dethroned by any number out of eleven if it was seen by electorates as not bringing the promised material reward. European governance in a global environment remains firmly national. 
